\title{
Methylnaltrexone in the treatment of opioid-induced constipation
}

\author{
Beverley Greenwood-Van \\ Meerveld' \\ Kelly M Standifer ${ }^{2}$ \\ 'Veterans Affairs Medical Center, \\ Oklahoma Center for Neuroscience, \\ Department of Physiology, University \\ of Oklahoma Health Sciences \\ Center, Oklahoma City, OK, USA; \\ ${ }^{2}$ Department of Pharmaceutical \\ Sciences, Oklahoma Center \\ for Neuroscience, University \\ of Oklahoma Health Sciences Center, \\ Oklahoma City, OK, USA
}

\begin{abstract}
Constipation is a significant problem related to opioid medications used to manage pain. This review attempts to outline the latest findings related to the therapeutic usefulness of a $\mu$ opioid receptor antagonist, methylnaltrexone in the treatment of opioid-induced constipation. The review highlights methylnaltrexone bromide (Relistor ${ }^{\mathrm{TM}}$; Progenics/Wyeth) a quaternary derivative of naltrexone, which was recently approved in the United States, Europe and Canada. The Food and Drug Administration in the United States approved a subcutaneous injection for the treatment of opioid bowel dysfunction in patients with advanced illness who are receiving palliative care and when laxative therapy has been insufficient. Methylnaltrexone is a peripherally restricted, $\mu$ opioid receptor antagonist that accelerates oral-cecal transit in patients with opioidinduced constipation without reversing the analgesic effects of morphine or inducing symptoms of opioid withdrawal. An analysis of the mechanism of action and the potential benefits of using methylnaltrexone is based on data from published basic research and recent clinical studies.
\end{abstract}

Keywords: methylnaltrexone, constipation, opioid

\section{Introduction}

Morphine and other opioid agonists are potent analgesics that represent the mainstay of therapy in the treatment of acute and chronic severe pain. Opioid analgesics work by predominantly stimulating $\mu$ opioid receptors in the central nervous system (CNS). However, constipation is a significant problem in patients taking opioid agonists for pain relief due primarily to their effect on $\mu$ opioid receptors located in the periphery within the gut itself. This review will focus on one of the currently available $\mu$ opioid receptor antagonists, specifically methylnaltrexone bromide (Relistor ${ }^{\mathrm{TM}}$; Progenics/ Wyeth), a quaternary derivative of naltrexone which was recently approved by the Food and Drug Administration (FDA) as a subcutaneous injection for the treatment of opioid bowel dysfunction in patients with advanced illness who are receiving palliative care and when laxative therapy has been insufficient. ${ }^{1}$ The review will provide an overview of methylnaltrexone's ability to promote gastrointestinal (GI) motility in patients with opioid-induced constipation without compromising the analgesic effects of morphine or stimulating symptoms of opioid withdrawal. The later sections of the review will discuss the potential use of methylnaltrexone for the treatment of constipation associated with post-operative ileus.

\section{Effect of opioids on gastrointestinal motility}

In the CNS the $\mu$ opioid receptor is the primary opioid receptor involved in pain transmission. Although there is limited evidence to suggest that centrally located $\mu$ opioid receptors may be involved in the control of GI transit, the dominant effect of the $\mu$ opioid receptor agonist, morphine, on the GI tract appears to occur via $\mu$ opioid receptors located peripherally within the gut wall. ${ }^{2,3}$ Recent evidence has demonstrated $\mu$ opioid receptors in enteric nervous system, specifically the submucosal 
and myenteric plexus in association with interstitial cells of Cajal. The muscle layers of the small and large intestine also have shown $\mu$ opioid receptor immunoreactivity. For excellent reviews of the anatomical distribution and function of the $\mu$ opioid receptor in the GI tract the reader is referred to Sternini and colleagues. ${ }^{4-6}$ Within the GI tract classical animal experiments demonstrated that morphine, fentanyl and met-enkephalin cause inhibition of both the longitudinal and circular muscle layers. ${ }^{7}$ More recent studies using a vascularly perfused intestinal segment demonstrated that morphine, dermorphin, D-Ala ${ }^{2}$-D-Met ${ }^{5}$-enkephalin, FK 33-824 and dynorphin reduced the frequency of peristaltic waves and the maximal ejection pressure. ${ }^{8}$ From multiple studies and clinical experience, a delay in GI transit is a well known characteristic of $\mu$ opioid receptor agonists including morphine, diphenoxylate and loperamide. ${ }^{9}$ The effects of opioids in delaying intestinal transit is speciesdependent and interspecies differences must be taken into account when examining the contribution of opioid agonists on GI motility. The delay in GI transit with opioid agonists occurs through either an inhibition of propulsive motility (rat) or a stimulation of non-propulsive or segmental patterns of motility in dog and man. ${ }^{10}$ The in vivo effects of opioid agonists to delay GI transit is due to an inhibition of the release of acetylcholine as well as to the release of nonadrenergic-noncholinergic (NANC) neurotransmitters from enteric nerves. ${ }^{11}$ These effects are mediated at least in part via $\mu$ opioid receptors present on circular muscle motor neurons. ${ }^{12}$ Moreover, in the rat ileum, selective agonists of $\mu$ (PLO17) and $\kappa(\mathrm{U}-50488)$ receptors inhibit neurotransmitter release along the ascending excitatory reflex pathway. ${ }^{13}$ A detailed review of the literature reveals that $\delta$ opioid receptors also are involved in the effects of opioids on motility. Delta receptors do not regulate the activity of myenteric excitatory motor neurons, since selective $\delta$ receptor agonists (DPDPE) or antagonists (ICI174864) are ineffective. ${ }^{14}$ However, in the circular muscle of the guinea pig and human colon, NANC inhibitory motor responses are reduced by activation of $\delta$ receptors. ${ }^{15,16}$

In summary, morphine or morphine-like opioid agonists induce a delay in GI transit and are involved in the development of opioid bowel dysfunction through a mechanism involving predominantly $\mu$ opioid receptors located within the GI tract.

\section{Opioid bowel dysfunction}

Opioid analgesics represent an important therapy for pain management, however opioids also have significant effects on GI motility to delay GI transit and cause constipation that may be so severe that it can limit pain management. Opioids delay GI transit via an inhibition of gastric emptying, a slowing of small and large bowel transit and an increase in anal sphincter tone due to activation of $\mu$ opioid receptors located in the GI tract. ${ }^{17-19}$ As early as 1917, Trendelenburg demonstrated in an isolated preparation of guinea-pig small intestine that morphine inhibits peristalsis. ${ }^{7}$ Since then many studies have confirmed that morphine and related opioids delay transit throughout the GI tract via a peripheral mechanism. Although peripherally restricted $\mu$ opioid receptor agonists such as loperamide have been shown to slow GI transit and are useful for the treatment of diarrhea ${ }^{9}$, the constipating effects of morphine that acts at both central and peripheral $\mu$ opioid receptors is a significant problem in patients receiving morphine for the relief of pain. Stimulation of the $\mu$ opioid receptors in the GI tract by morphine frequently results in unwanted effects termed opioid bowel dysfunction. Opioid bowel dysfunction is characterized by severe constipation, hard stools, straining, incomplete evacuation, bloating, abdominal distension, and increased gastroesophageal reflux..$^{20-22}$ It is estimated that about $40 \%$ of patients taking chronic opioids for pain develop opioid bowel dysfunction. ${ }^{20}$ Clearly, the mechanisms of opioid bowel dysfunction are complex; however studies have shown that gut hypomotility correlates with opioid concentration in the enteric nervous system ${ }^{21}$ and the morphineinduced inhibition of GI transit results from activation of $\mu$ opioid receptors in the gut. ${ }^{22}$ Interestingly, although patients develop tolerance to opioid-induced nausea, vomiting and sedation, they rarely develop tolerance to the delayed GI transit and resulting constipation induced by opioids. ${ }^{23}$ In summary, chronic opioid use for severe pain is associated with significant adverse effects including opioid-induced bowel dysfunction characterized by constipation that is often not relieved by laxatives..$^{24-26}$

\section{Therapeutic approaches for treating opioid-induced constipation Laxatives and promotility agents}

Until recently the management of opioid-induced bowel dysfunction was limited to use of a stimulate laxative such as bisacodyl or senna with or without addition of stool softeners such as docusate sodium or lactulose ${ }^{24-26}$ as well as increasing dietary fiber, increasing fluid intake and/or suggesting daily exercise whenever possible to treat the constipation. Osmotic laxatives and bulk forming laxatives also have been employed in patients with opioid-induced bowel dysfunction but they must be used cautiously in patients 
requiring fluid restriction, bedridden patients or those with strictures or partial bowel obstruction. ${ }^{26,27}$ Often increased fiber intake or use of bulk laxatives increase pressure in the gut, worsening the patient's pain and increasing their discomfort. Promotility agents such as metaclopramide, a dopamine $\mathrm{D}_{2}$ receptor antagonist, also are used to accelerate GI transit in a subset of patients with delayed GI transit suffering from GI autonomic dysfunction. ${ }^{27}$ Although laxatives are beneficial in some patients, they are poorly effective in most and opioid-induced bowel dysfunction persists despite aggressive laxative therapy. Until recently laxatives represented the mainstay of therapy for the treatment of opioid-induced constipation, despite their serious limitations.

\section{Opioid receptor antagonists}

In very severe cases of opioid-induced constipation patients reduce their use of opioids to alleviate the constipation despite the resulting loss of adequate pain relief. The first competitive opioid antagonists that were used to treat opioid bowel dysfunction included naloxone, naltrexone and nalmefene. While these antagonists were selective for opioid receptors, they were not selective for the periphery, and have both central and peripheral activity due to their ability to cross the blood brain barrier. Although such compounds were able to increase laxation in patients with opioid-induced constipation, they also were associated with symptoms of opioid withdrawal and a marked decrease in adequate pain relief due to the effects of the compounds on central $\mu$ opioid receptors. Thus the search was initiated for an opioid antagonist that possessed the capability of reversing opioidinduced constipation without reducing the level of analgesia or stimulating opioid withdrawal. It was suggested in the latter part of the twentieth century that quaternary narcotic antagonists might be useful to treat opioid-induced peripheral side effects since some of these agents failed to cross the blood brain barrier readily. ${ }^{28,29}$ Quaternary opioid antagonists were developed that had increased polarity and decreased lipid solubility and a reduced ability to cross the blood brain barrier following systemic administration. As a result, these compounds bound only to peripheral $\mu$ receptors unless administered directly into the brain. ${ }^{28,29}$ Today peripheral $\mu$ opioid receptor antagonism offers a newly approved class of therapeutics for the treatment of constipation associated with the long-term use of opioids while preserving centrally mediated analgesia. ${ }^{1}$ A major focus of the subsequent section of this review will be the use of methylnaltrexone for the treatment of opioid-induced bowel dysfunction, specifically severe constipation in patients receiving opioid therapy for pain management.

\section{Effect of methylnaltrexone in preclinical experimental models}

An extensive series of studies were designed to characterize the pharmacological profile of methylnaltrexone. Until recently, opioid receptor affinity was assessed in whole rat brain or guinea pig ileum tissue by displacing the binding of non-selective opioid antagonists, ${ }^{3} \mathrm{H}$-etorphine or ${ }^{3} \mathrm{H}$-diprenorphine. These studies revealed that the quaternary derivative of naltrexone exhibited only $1 \%$ to $3 \%$ of the affinity for the $\mu$ opioid receptor as naltrexone itself. $^{30}$ Assessment of the affinities and selectivity of methylnaltrexone for $\mu, \delta$ and $\kappa$ opioid receptors recently was performed in cells expressing recombinant human opioid receptors as well as in animal tissues expressing endogenous opioid receptors. These studies demonstrated that the compound displaced opioid binding to $\mu$ opioid receptors with an affinity of $10 \mathrm{nM}$, and a 3-fold lower affinity for $\kappa$ opioid receptors $\left(\mathrm{K}_{\mathrm{i}} 30 \mathrm{nM}\right) .{ }^{31}$ These studies also demonstrated that the affinity of methylnaltrexone for $\delta$ opioid receptors is much less $\left(\mathrm{K}_{\mathrm{i}} 15.8 \mu \mathrm{M}\right) .{ }^{31}$ While initial reports indicated that methylnaltrexone had no intrinsic opioid agonist activity, ${ }^{28-30}$ more recent studies comparing it against a variety of opioid antagonists demonstrated that the compound exhibited weak partial agonist activity at recombinant $\mu$ and $\kappa$ opioid receptors (intrinsic activity 10 and 12 , respectively). ${ }^{31}$ Using in vitro and in vivo models the effect of methylnaltrexone on the GI tract was systematically studied. Methylnaltrexone reversed morphine-induced inhibition of gut contractility in isolated guinea-pig ileum and human small intestine. ${ }^{31,32}$ A limited number of studies have also suggested that there may be endogenous inhibitory opioid tone of the GI musculature since methylnaltrexone alone enhanced muscle contractility in tissue isolated from the human ${ }^{32}$ or equine ${ }^{33} \mathrm{GI}$ tract. However, effects of methylnaltrexone on electricallyevoked contraction of guinea pig ileum muscle strips are mixed, with methylnaltrexone inhibiting contractions in one study ${ }^{31}$ and exacerbating contractions in another. ${ }^{32}$ Some of these differences may result from differences in electrical current applied to the tissue in the two experiments, as well as to different levels of endogenous opioid inhibitory tone between species. However, whether methylnaltrexone has therapeutic potential in other GI disorders characterized by hypomotility requires further research. The effect of methylnaltrexone on GI transit in vivo demonstrated that methylnaltrexone at doses of 1,3 and $10 \mathrm{mg} / \mathrm{kg}$, administered subcutaneously, 
effectively antagonized morphine-induced inhibition of GI transit in rats. ${ }^{34}$ To test the hypothesis that antagonism of the effects of opioids in the gut can be accomplished without compromising analgesia, experimental models demonstrated that subcutaneous administration of methylnaltrexone had no effect on morphine-induced analgesia whereas if the methylnaltrexone was administered directly into the brain there was a marked reduction in analgesia. ${ }^{34,35}$

In summary, the efficacy of methylnaltrexone to antagonize the GI-mediated events effects of morphine occurred at doses that failed to antagonize morphineinduced analgesia. Early preclinical experiments were also conducted with methylnaltrexone to ensure that following intravenous administration there were no signs or symptoms of withdrawal in opioid-tolerant dogs. ${ }^{28}$ The study found that in response to doses of methylnaltrexone as high at $50 \mathrm{mg} / \mathrm{kg}$ there were no symptoms of withdrawal whereas signs of withdrawal were noted with doses of naltrexone as low as $0.5 \mathrm{mg} / \mathrm{kg} .{ }^{28,36}$

\section{Clinical pharmacology of methylnaltrexone}

A summary of the efficacy and pharmacokinetic characteristics of methylnaltrexone in healthy human subjects, as well as patients with advanced illness or on chronic methadone treatment are provided in Table 1. With iv or sc delivery, methylnaltrexone is rapidly absorbed in a dose-dependent manner, with a peak concentration $\left(\mathrm{C}_{\max }\right)$ generally reached within 20 to 30 minutes $\left(\mathrm{T}_{\max }\right)$ and $\tau_{1 / 2}$ of elimination is 100 to 130 minutes. ${ }^{37-39}$ While orally administered methylnaltrexone is absorbed in a dose-dependent manner, far less is absorbed in general, maximal blood levels are not achieved until almost 2 hours, and the $\tau_{1 / 2}$ is around 3 hours. ${ }^{40}$ The primary pathways of metabolism are the conversion to methyl-6-naltrexol isomer ( $5 \%$ of the total) and methylnaltrexone sulphate $(1.3 \%$ of the total). N-methylation of methylnaltrexone to naltrexone is not a significant issue. ${ }^{41}$ The excretion of methylnaltrexone is via the urine and feces and approximately $40 \%$ to $50 \%$ of the compound is excreted unchanged in the urine following sc or iv. administration. ${ }^{37-39,42,43}$ Interestingly, following oral administration, only a tiny fraction of methylnaltrexone is excreted unchanged $(0.3 \%$ or less $) .{ }^{40,44}$ Almost a 100 -fold higher dose of oral methylnaltrexone $(19.2 \mathrm{mg} / \mathrm{kg})^{40}$ was required to produce maximal plasma concentrations equivalent to those produced by $0.1 \mathrm{mg} / \mathrm{kg} \mathrm{sc} .{ }^{39}$ or $0.16 \mathrm{mg} / \mathrm{kg}$ iv methylnaltrexone. ${ }^{37}$ Since only a fraction of the methylnaltrexone was excreted unchanged yet maintained its ability to antagonize morphine-induced oral-cecal transit delay
(Table 1), this suggests that the majority of the compound remained in the GI tract instead of being absorbed into the bloodstream. ${ }^{40,44}$ An enteric-coated formulation of methylnaltrexone was effective orally at only $3.2 \mathrm{mg} / \mathrm{kg}$. ${ }^{44}$

\section{Clinical efficacy studies of methylnaltrexone for opioid-induced constipation}

In early clinical studies, methylnaltrexone was used as a pharmacological tool to examine the relative importance of peripheral opioid receptor antagonism in modulating opioidinduced delay in gastric emptying ${ }^{45}$ as well as oral-cecal transit. ${ }^{38}$ In the first human study to demonstrate that opioids affect gastric emptying via a peripheral mechanism distinct from the central analgesic effects of opioids, 11 healthy controls were given placebo (saline) plus morphine or methylnaltrexone plus morphine in a randomized doubleblind crossover controlled trial. ${ }^{45}$ The results showed that morphine prolonged gastric emptying and that methylnaltrexone prevented the morphine-induced gastric emptying. In 1996, Yuan et al reported that methylnaltrexone blocked morphine-induced oral-cecal transit delay with no effect on morphine analgesia, demonstrating for the very first time in human that opioid effects on the gut are mediated through peripheral $\mu$ opioid receptors distinct from those receptors located centrally that mediate analgesia. ${ }^{38}$

This and other studies performed in healthy volunteers measured the ability of methylnaltrexone to reverse morphineinduced oral to cecal transit time using the lactulose hydrogen breath test; ${ }^{38,39,44,46}$ pain intensity in response to the cold pressor test was assessed in one study to measure levels of pain reporting in the same subjects. ${ }^{38}$ Methylnaltrexone administered intravenously, orally or subcutaneously reversed the delay in oral-cecal transit induced by morphine ${ }^{38,39,44,46}$ without any effect on levels of analgesia. ${ }^{38}$ Furthermore, in a randomized placebocontrolled trial, methylnaltrexone administered intravenously at a cumulative low dose ranging from $0.015-0.365 \mathrm{mg} / \mathrm{kg}$ to 11 subjects with chronic methadone-induced constipation reversed the opioid-induced increase in GI transit time and produce immediate laxation in $91 \%$ of patients on day 1 and $100 \%$ of the patients by the morning of the second day of $\operatorname{dosing}^{43}$ (Table 1). More recently in one small study and then two larger pivotal studies, the effectiveness of methylnaltrexone was investigated in patients with advanced illness with a life expectancy of less than 6 months, who were receiving palliative opioid therapy and had opioid-induced constipation (defined as fewer than 3 bowel movements in the preceding week or no bowel movement for 2 days). Rescue laxatives were prohibited 


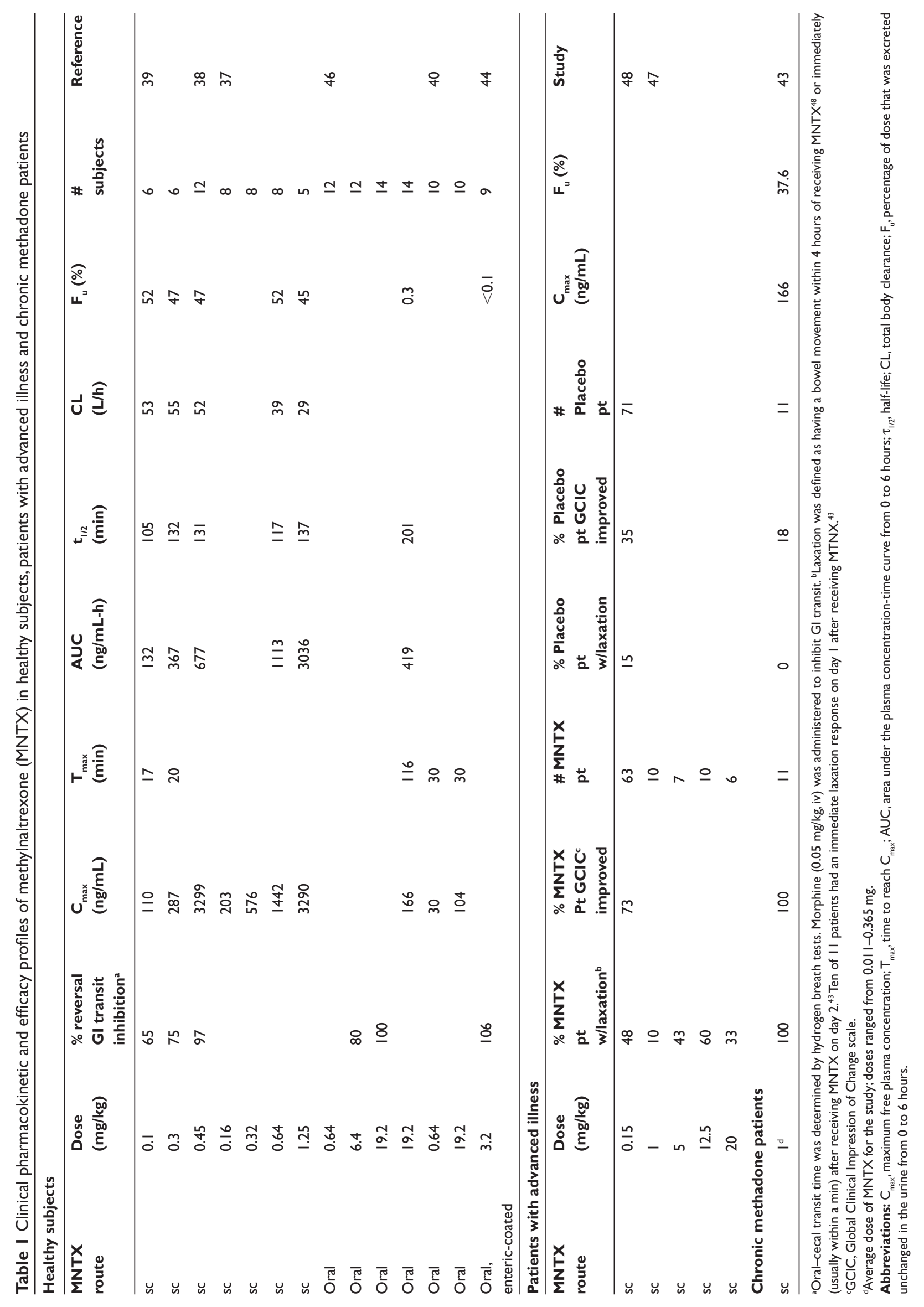


from 4 hours before until 4 hours after receiving the injection of methylnaltrexone. A double-blind, randomized parallel group, dose ranging study was conducted by Portenoy and colleagues in 33 adult patients with advanced illness defined as terminal or end stage diseases such as advanced metastatic cancer or AIDS. ${ }^{47}$ Methylnaltrexone at doses of 5, 12.5 and $20 \mathrm{mg}$ ( $0.05-0.5 \mathrm{mg} / \mathrm{kg} \mathrm{sc})$ induced a bowel movement within 4 hours in $33 \%$ to $60 \%$ of patients; this was reproducible with repeated dosing and occurred in the absence of opioid withdrawal or loss of adequate pain control. In a larger Phase III study where the primary end point was the proportion of patients with a rescue-free laxation within 4 hours of receiving the medication, the goal was to compare a single, double blind subcutaneous dose of methylnaltrexone $(0.15 \mathrm{mg} / \mathrm{kg}$ or $0.3 \mathrm{mg} / \mathrm{kg})$ versus placebo. The double blind dose was followed by an open-label 4 week dosing period during which time methylnaltrexone could be used as needed but no more that 1 dose in a 24-hour period. In the double blind period 154 patients were enrolled (47 patients received methylnaltrexone $0.15 \mathrm{mg} / \mathrm{kg}$, 55 methylnaltrexone $0.3 \mathrm{mg} / \mathrm{kg}$ and 52 placebo). The results showed that $62 \%$ of the patients receiving $0.15 \mathrm{mg} / \mathrm{kg}$ methylnaltrexone and $58 \%$ of those receiving $0.3 \mathrm{mg} / \mathrm{kg}$ methylnaltrexone had a significantly higher rate of laxation within 4 hours of the double-blind dose compared to $14 \%$ treated with placebo. ${ }^{41}$ Similar results were report in another Phase III study published by Thomas and colleagues in $2008 .{ }^{48}$ A total of 133 patients who were using opioids for pain relief for at least 2 weeks and were taking laxatives without relief for their opioid-induced constipation were randomly assigned to receive either subcutaneous methylnaltrexone $(0.15 \mathrm{mg} / \mathrm{kg}, 62$ patients $)$ or placebo (71 patients) every other day for a week. During the second week the dose of the compound could be increased $0.30 \mathrm{mg} / \mathrm{kg}$ if the patient had 2 or less rescue-free laxations up to day 8 . The study found that $48 \%$ of patients receiving methylnaltrexone had a bowel movement within 4 hours of the first dose while only $15 \%$ of patients receiving placebo had a bowel movement within 4 hours. However, when the patients were asked to self assess improvement in their bowel status using a Global Clinical Impression of Change (GCIC) Scale after 7 and 14 days, most patients (73\%) reported increased satisfaction following methylnaltrexone therapy compared to only $35 \%$ of patients in the placebo group, suggesting that methylnaltrexone improved the constipating symptoms in over $70 \%$ of patients. An important component of the study was that no significant changes in pain scores were observed and there were no signs of opioid withdrawal. ${ }^{48}$ This and other clinical studies have also assessed the occurrence of methylnaltrexone-related adverse effects. . $3,37,43,45,47,48$ There was no dose-dependence associated with the adverse effects, which were generally gastrointestinal in nature (abdominal pain, diarrhea, flatulence and nausea) and tolerable. In fact, these side effects are common to existing treatments for opioid-induced constipation. In a dose-escalating study in which methylnaltrexone was iv infused, a few subjects reported transient orthostatic hypotension, that resolved quickly. ${ }^{37}$ The rates of discontinuation due to adverse events during the double-blind placebo controlled clinical trials described above were comparable for methylnaltrexone $(1.2 \%)$ and placebo (2.4\%); no serious adverse effects were attributed to methylnaltrexone.

In summary, the results showed that in these specific patient groups with advanced illness, methylnaltrexone administered subcutaneously, relieved opioid-induced constipation but most importantly did not reduce analgesia or cause any symptomatology associated with opioid withdrawal. Methylnaltrexone was effective in almost $70 \%$ of those patients studied, and it is hoped that further clinical studies will be performed in patients with less advanced disease. In addition to the currently approved subcutaneous route of administration for methylnaltrexone, its future development involves multiple routes of administration including oral/oral enteric-coated oral forms of methylnaltrexone for opioid-induced constipation and an intravenous formulation for post-operative ileus.

\section{Potential use of methylnaltrexone for the treatment of post-operative ileus}

Although quite different from opioid bowel dysfunction in the setting of chronic opioid administration, another common condition termed post-operative ileus is a transient impairment of GI motility that routinely develops as a consequence of abdominal surgery. Although the pathophysiology of post-operative ileus is very complex involving inflammatory, neural and hormonal mechanisms, there is a significant pharmacological component to post-operative ileus. Specifically the use of opioid drugs, such as morphine for the management of post-operative pain, is well known to exacerbate the severity of post-operative ileus (see review ${ }^{49}$ ). In fact a retrospective study of post-operative ileus patients identified that the use of opioid-based analgesics represent a key risk factor for the development of ileus following surgery..$^{50}$ Usually patients recover from post-operative ileus in 1 to 2 days, particularly after laparoscopic bowel surgery. However, prolonged and untreated post-operative ileus may require nasogastric intubation and sometimes even parenteral nutrition. The duration of ileus following surgery is dependent on which part of the 
GI tract is most affected, with the small intestine recovering within the first 24 hours whereas the stomach (24-48 hours) and the colon require longer (48-72 hours) recovery periods. Certain patients who are less mobile post-surgery have been found to be more susceptible to post-operative ileus. Delayed gastric emptying and intestinal transit are the main factors leading to symptoms of post-operative ileus which include abdominal bloating and pain, nausea and vomiting, anorexia, and reduced defecation.

In addition to postoperative opioid dosage, the duration of post-operative ileus following colorectal surgery also is positively correlated with the amount of blood loss and surgery time. ${ }^{51}$ Although the analgesic effects of opioids, such as morphine, are predominantly mediated by $\mu$ opioid receptors in the CNS, the action of morphine to delay GI transit involves predominantly activation of $\mu$ opioid receptors in the periphery to inhibit enteric reflexes and suppress GI transit. ${ }^{16}$ Despite the fact that post-operative abnormalities in GI transit are common and can significantly delay a patient's recovery, the pathophysiological mechanisms causing post-operative ileus are incompletely understood. ${ }^{52}$ Research from animal studies has shown abdominal surgery stimulates capsaicin-sensitive afferent fibers that lead to activation of inhibitory efferent pathways and disrupt coordinated patterns of GI motility. Evidence is greatest for adrenergic receptor mediated pathways that involve alpha receptors located on vagal nerve terminal and postganglionic cholinergic nerves in the myenteric plexus that inhibit the release of acetylcholine in post-operative ileus. ${ }^{53}$ Thus neural pathways producing post-operative ileus are complex and dependent on a number of factors including the magnitude and intensity of the stimulus. For example, incision of the skin and laparotomy stimulate adrenergic inhibitory neuronal pathways, ${ }^{54,55}$ whereas abdominal surgery with handling of the intestine activates supra-spinal pathways that involve stimulation of the hypothalamic pituitary adrenal (HPA) stress axis and release of corticotrophin-releasing factor (CRF). ${ }^{56-58}$ In addition, non-adrenergic, non-cholinergic (NANC) neuronal pathways may also inhibit GI motility. Multiple inhibitory NANC neurotransmitters such as nitric oxide (NO), calcitonin gene-related peptide (CGRP) and vasoactive intestinal polypeptide (VIP) are present within the enteric nervous systems, and they too may play an important role in the pathogenesis of post-operative ileus. ${ }^{59-61}$ Recent findings have also shown that manipulation of the bowel during surgery induces a marked intestinal inflammation in rodents. ${ }^{62-65}$ These studies showed that specific inflammatory cells such as monocytes, neutrophils and mast cells increase in response to bowel manipulation, and there was a marked induction within the GI musculature of inducible nitric oxide synthase (iNOS) and cyclo-oxygenase-2 (COX-2) mRNA. The inflammatory response induced by bowel manipulation also leads to the secretion of a series of pro-inflammatory cytokines, including interleukin-1 $\beta$, interleukin-6, tissue necrosis factor- $\alpha$ and monocyte chemotactic protein-1. There is also evidence that bowel manipulation up-regulates adhesion molecules such as intercellular adhesion molecule-1 (ICAM-1), and that the ICAM-1 antisense oligonucleotide ISIS 3082 prevents the development of ileus in mice. ${ }^{66}$ Interestingly, in an animal model of post-operative ileus produced by bowel manipulation, the magnitude of the inflammatory response appeared to be proportional to the decrease in GI transit measured in vivo and the loss of smooth muscle contractility observed in an organ bath preparation. $^{67,68}$

The development of new pharmacological strategies to accelerate the recovery from POI are urgently needed because post-surgical GI dysmotility represents a major health problem contributing to patient morbidity, prolonged hospital stays and increased health care costs. Recently positive clinical efficacy data obtained with a peripherally acting antagonist of the $\mu$ opioid receptor, alvimopan, in treating the delay in GI transit following surgery led to its recent approval by the FDA for treatment of post-operative ileus. However, clinical reports related to the efficacy of methylnaltrexone for the treatment of post-operative ileus have been inconclusive to date. In a Phase II trial performed in 65 patients with post-operative ileus induced by colonic resection, administration of methylnaltrexone (0.3 $\mathrm{mg} / \mathrm{kg}$, intravenous) after surgery every 6 hours for 24 hours recovered from post-operative ileus 1 day faster than those receiving placebo as assessed by time to first bowel movement, ability to tolerate food and hospital discharge. ${ }^{69}$ However, those findings were not supported by preliminary results from a Phase III trial of 542 patients with post-operative ileus; methylnaltrexone administered at 12 or $24 \mathrm{mg}$ every $6 \mathrm{hr}$ did not show efficacy over placebo. ${ }^{70}$ At the time of this review, a second Phase III trial is underway with preliminary results suggesting that methylnaltrexone was not different from placebo in treating post-operative ileus. ${ }^{70}$ The reason for these differences in clinical efficacy between alvimopan and methylnaltrexone for the treatment of post-operative ileus remains to be determined but while both alvimopan and methylnaltrexone share many pharmacological properties, there are a few notable differences. Evidence suggests that alvimopan 
has inverse agonist activity in the guinea pig ileum assay while methylnaltrexone does not. ${ }^{8}$ If the various conditions associated with post-operative ileus described above contribute to impaired GI transit, one can see how an antagonist with inverse agonist properties might more effectively increase gut motility than one with very weak partial agonist activity. Alvimopan also exhibits a slightly greater $\mu / \kappa$ opioid receptor selectivity ratio. ${ }^{30}$

Finally, it has been proposed that P-glycoprotein (P-gp) expression in the small intestine may affect the response of the small intestine to chronic drug treatment. ${ }^{71}$ For instance, while tolerance does not develop to the constipating effects of morphine, tolerance does develop to the inhibitory GI transit effects of loperamide. This difference may be attributed to the fact that loperamide is a better substrate for P-gp than morphine. To date, there are no reports on the affinity of either methylnaltrexone or alvimopan for P-gp or other drug transporters, but expression of these transporters is altered (generally reduced) by acute activation of inflammatory mediators such as iNOS, interleukin-1 $\beta$, interleukin-6 and tumor necrosis factor- $\alpha .^{72-75}$ Reduced expression of P-gp or other drug efflux transporters could increase the level of drug in the gut tissue and increase its efficacy. Finally, the lack of efficacy of methylnaltrexone for the treatment of post-operative ileus may relate to the design of the clinical trails, dosage and route of administration, and such factors are currently under investigation.

\section{Conclusions and future directions}

Although the actions of opioids in the gut have been well documented, major gaps remain in our understanding of the precise mechanisms underlying these effects, and of the potential role of opioid systems in GI diseases. Opioid analgesic use is commonly associated with GI side effects suggesting a role for opioid systems in both GI function and pathophysiology. The use of $\mu$ opioid receptor antagonists with activity limited to the periphery has proven to be of benefit in the clinic, where peripherally acting $\mu$ opioid antagonists, such as methylnaltrexone, reverse the unwanted peripheral side effect of constipation associated with opioid therapy while preserving centrally mediated opioid analgesia. Taken together, the preclinical data on methylnaltrexone are consistent with the clinical reports confirming the ability of methylnaltrexone to antagonize opioid-induced constipation without reversing analgesia or precipitating withdrawal symptoms. Additional research is required to determine whether methylnaltrexone also will be useful for the treatment of post-operative ileus.

\section{Disclosures}

The authors have no conflicts of interest to disclose.

\section{References}

1. Lang L. The Food and Drug Administration approves methylnaltrexone bromide for opioid-induced constipation. Gastroenterology. 2008;135(1):6.

2. Manara L, Bianchetti A. The central and peripheral influence of opioids on gastrointestinal propulsion. Annu Rev Pharmacol Toxicol. 1985;25:249-273.

3. Manara L, Bianchi G, Ferretti P, Tavani A. Inhibition of gastrointestinal transit by morphine in rats results primarily from direct drug action on the gut opioid sites. J Pharmacol Exp Ther. 1986;237(3):945-949.

4. Sternini C. Receptors and transmission in the brain-gut axis: potential for novel therapies. III. Mu-opioid receptors in the enteric nervous system. Am J Physiol Gastrointest Liver Physiol. 2001;281(1):G8-G15.

5. Sternini C. Patierno S, Selmer IS, Kirchgessner A. The opioid system in the gastrointestinal tract. Neurogastroenterol Motil. 2004;16(Suppl 2):3-16.

6. DeHaven-Hudkins DL, DeHaven RN, Little PJ, Techner LM. The involvement of the mu-opioid receptor in gastrointestinal pathophysiology: therapeutic opportunities for antagonism at this receptor. Pharmacol Ther. 2008;117(1):162-187.

7. Trendelenburg P. [Physiological and pharmacological investigations of small intestinal peristalsis]. Naunyn Schmiedebergs Arch Pharmacol. 1917;81(1):55-129.

8. Sanger GJ, Tuladhar BR. The role of endogenous opioids in the control of gastrointestinal motility: prediction from in vitro modelling. Neurogastroenterol Motil. 2004;16(Suppl 2):38-45.

9. Ooms LA, Degryse AD, Janssen PA. Mechanisms of action of loperamide. Scand J Gastroenterol Suppl. 1984:96:145-155.

10. Bueno L, Fioramonti J. Action of opiates on gastrointestinal function. Baillieres Clin Gastroenterol. 1988;2(1):123-139.

11. Wood JD, Galligan JJ. Function of opioids in the enteric nervous system. Neurogastroenterol Motil. 2004;16(Supp1 2):17-28.

12. Tonini M, Waterman SA, Candura SM, Coccini T, Costa M. Sites of action of morphine on the ascending excitatory reflex in the guinea-pig small intestine. Neurosci Lett. 1992;144(1-2):195-198.

13. Allescher HD, Storr M, Brechmann C, Hahn A, Schusdziarra V. Modulatory effect of endogenous and exogenous opioids on the excitatory reflex pathway of the rat ileum. Neuropeptides. 2000;34(1):62-68.

14. Kojima Y, Takahashi T, Fujina M, Owyang C. Inhibition of cholinergic transmission by opiates in ileal myenteric plexus is mediated by kappa receptor. Involvement of regulatory inhibitory $\mathrm{G}$ protein and calcium N-channels. J Pharmacol Exp Ther. 1994;268(2):965-970.

15. Hoyle CH, Kamm MA, Burnstock G, Lennard-Jones JE. Enkephalins modulate inhibitory neuromuscular transmission in circular muscle of human colon via delta-opioid receptors. J Physiol. 1990;431:465-478.

16. Zagorodnyuk V, Maggi CA. Electrophysiological evidence for different release mechanism of ATP and NO as inhibitory NANC transmitters in guinea-pig colon. Br J Pharmacol. 1994;112(4):1077-1082.

17. De Luca A, Coupar IM. Insights into opioid action in the intestinal tract. Pharmacol Ther. 1996;69(2):103-115.

18. Friedman JD, Dello Buono FA. Opioid antagonists in the treatment of opioid-induced constipation and pruritus. Ann Pharmacother. 2001;35(1):85-91.

19. Greenwood-Van Meerveld B, Gardner CJ, Little PJ, Hicks GA, DeHaven-Hudkins DL. Preclinical studies of opioids and opioid antagonists on gastrointestinal function. Neurogastroenterol Motil. 2004;16(Suppl 2):46-53.

20. Pappagallo M. Incidence, prevalence and management of opioid bowel dysfunction. Am J Surg. 2001;182(5A Suppl):11S-18S.

21. Thomas J. Opioid-induced bowel dysfunction. J Pain Symptom Manage. 2008;35(1):103-113. 
22. Foss JF. A review of the potential role of methylnaltrexone in opioid bowel dysfunction. Am J Surg. 2001;182(5A Suppl):19S-26S.

23. McNicol ED, Boyce D, Schumann R, Carr DB. Mu-opioid antagonists for opioid-induced bowel dysfunction. Cochrane Database Syst Rev. 2008;(2):CD006332

24. Walsh TD. Prevention of opioid side effects. J Pain Symptom Manage. 1990;5(6):362-367.

25. Glare P, Lickiss JN. Unrecognized constipation in patients with advanced cancer: a recipe for therapeutic disaster. J Pain Symptom Manage. 1992;7(6):369-371.

26. Swegle JM, Logemann C. Management of common opioid-induced adverse effects. Am Fam Physician. 2006;74(8):1347-1354.

27. Lagman RL, Davis MP, LeGrand SB, Walsh D. Common symptoms in advanced cancer. Surg Clin North Am. 2005;85(2):237-255.

28. Russell J, Bass P, Goldberg LI, Schuster CR, Merz H. Antagonism of gut, but not central effects of morphine with quaternary narcotic antagonists. Eur J Pharmacol. 1982;78(3):255-261.

29. Brown DR, Goldberg LI. The use of quaternary narcotic antagonists in opiate research. Neuropharmacology. 1985:24(3):181-1 91.

30. Valentino RJ, Herling S, Woods JH, Medzihradsky F, Merz H. Quaternary naltrexone: evidence for the central mediation of discriminative stimulus effects of narcotic agonists and antagonists. J Pharmacol Exp Ther. 1981:217(3):652-659.

31. Beattie DT, Cheruvu M, Mai N, et al. The in vitro pharmacology of the peripherally restricted opioid receptor antagonists, alvimopan, ADL 08-0011 and methylnaltrexone. Naunyn Schmiedebergs Arch Pharmacol. 2007;375(3):205-220.

32. Yuan CS, Foss JF, Moss J. Effects of methylnaltrexone on morphineinduced inhibition of contraction in isolated guinea-pig ileum and human intestine. Eur J Pharmacol. 1995:276(1-2):107-111.

33. Van Hoogmoed LM, Boscan PL. In vitro evaluation of the effect of the opioid antagonist $\mathrm{N}$-methylnaltrexone on motility of the equine jejunum and pelvic flexure. Equine Vet J. 2005;37(4):325-328.

34. Gmerek DE, Cowan A, Woods JH. Independent central and peripheral mediation of morphine-induced inhibition of gastrointestinal transit in rats. J Pharmacol Exp Ther. 1986;236(1):8-13.

35. Walker MJ, Le AD, Poulos CX, Cappell H. Role of central versus peripheral opioid receptors in analgesia induced repeated administration of opioid antagonists. Psychopharmacology (Berl). 1991;104(2):164-166.

36. Valentino RJ, Katz JL, Medzihradsky F, Woods JH. Receptor binding, antagonist, and withdrawal precipitating properties of opiate antagonists. Life Sci. 1983;32(25):2887-2896.

37. Foss JF, O'Connor MF, Yuan CS, Murphy M, Moss J, Roizen MF. Safety and tolerance of methylnaltrexone in healthy humans: a randomized, placebo-controlled, intravenous, ascending-dose, pharmacokinetic study. J Clin Pharmacol. 1997;37(1):25-30.

38. Yuan CS, Foss JF, O'Conner M, Toledano A, Roizen MF, Moss J. Methylnaltrexone prevents morphine-induced delay in oral-cecal transit time without affecting analgesia: a double-blind randomized placebocontrolled trial. Clin Pharmacol Ther. 1996;59(4):469-475.

39. Yuan CS, Wei G, Foss JF, O'Connor M, Karrison T, Osinski J. Effects of subcutaneous methylnaltrexone on morphine-induced peripherally mediated side effects: a double-blind randomized placebo-controlled trial. J Pharmacol Exp Ther. 2002;300(1):118-123.

40. Yuan CS, Foss JF, O’Connor M, Osinski J, Roizen MF, Moss J. Efficacy of orally administered methylnaltrexone in decreasing subjective effects after intravenous morphine. Drug Alcohol Depend. 1998;52(2):161-165.

41. Full Prescribing Information. [linked PDF, cited 2008 Nov 14]. Available from: http://www.wyeth.com/hcp/relistor/landing.

42. Yuan CS, Foss JF, O'Connor M, Osinski J, Roizen MF, Moss J. Effects of intravenous methylnaltrexone on opioid-induced gut motility and transit time changes in subjects receiving chronic methadone therapy: a pilot study. Pain. 1999;83(3):631-635.

43. Yuan CS, Foss JF, O'Connor M, et al. Methylnaltrexone for reversal of constipation due to chronic methadone use: a randomized controlled trial. JAMA. 2000;283(3):367-372.
44. Yuan CS, Foss JF, O'Connor M, et al. Effects of enteric-coated methylnaltrexone in preventing opioid-induced delay in oral-cecal transit time. Clin Pharmacol Ther. 2000;67(4):398-404.

45. Murphy DB, Sutton JA, Prescott LF, Murphy MB. Opioid-induced delay in gastric emptying: a peripheral mechanism in humans. Anesthesiology. 1997;87(4):765-770.

46. Yuan CS, Foss JF, Osinski J, Toledano A, Roizen MF, Moss J. The safety and efficacy of oral methylnaltrexone in preventing morphineinduced delay in oral-cecal transit time. Clin Pharmacol Ther. 1997;61(4):467-475.

47. Portenoy RK, Thomas J, Moehl Boatwright ML, et al. Subcutaneous methylnaltrexone for the treatment of opioid-induced constipation in patients with advanced illness: a double-blind, randomized, parallel group, dose-ranging study. J Pain Symptom Manage. 2008;35(5):458-468.

48. Thomas J, Karver S, Cooney GA, et al. Methylnaltrexone for opioid-induced constipation in advanced illness. $N$ Engl $J$ Med. 2008;358(22):2332-2343

49. Greenwood-Van Meerveld B. Emerging drugs for postoperative ileus. Expert Opin Emerg Drugs. 2007;12(4):619-626.

50. Senagore AJ. Overview of POI and its impact on surgical outcomes. Contemporary Surg. 2006; March Suppl:4-7.

51. Artinyan A, Nunoo-Mensah JW, Balasubramaniam S, et al. Prolonged postoperative ileus-definition, risk factors and predictors after surgery. World J Surg. 2008;32(7):1495-1500.

52. Bauer AJ, Boeckxstaens GE. Mechanisms of postoperative ileus. Neurogastroenterol Motil. 2004;16(Suppl 2):54-60.

53. Sagrada A, Fargeas MJ, Bueno L. Involvement of alpha-1 and alpha-2 adrenoceptors in the postlaparotomy intestinal motor disturbances in the rat. Gut. 1987;28(8):955-959.

54. Boeckxstaens GE, Hirsch DP, Kodde A, et al. Activation of an adrenergic and vagally mediated NANC pathway in surgery-induced fundic relaxation in the rat. Neurogastroenterol Motil. 1999;11(6):467-474.

55. Holzer P, Lippe IT, Amann R. Participation of capsaicin-sensitive afferent neurons in gastric motor inhibition caused by laparotomy and intraperitoneal acid. Neuroscience. 1992;48(3):715-722.

56. Barquist E, Bonaz B, Martinez V, Rivier J, Zinner MJ, Tache Y. Neuronal pathways involved in abdominal surgery-induced gastric ileus in rats. Am J Physiol. 1996;270(4 Pt 2):R888-R894.

57. Bonaz B, Tache Y. Corticotropin-releasing factor and systemic capsaicin-sensitive afferents are involved in abdominal surgery-induced Fos expression in the paraventricular nucleus of the hypothalamus. Brain Res. 1997;748(1-2):12-20.

58. Tache Y, Monnikes H, Bonaz B, Rivier J. Role of CRF on stress-related alterations of gastric and colonic motor function. Ann N Y Acad Sci. 1993;697:233-243.

59. De Winter BY, Boeckxstaens GE, De Man JG, Moreels TG, Herman AG, Pelckmans PA. Effect of adrenergic and nitrergic blockade on experimental ileus in rats. Br J Pharmacol. 1997;120(3):464-468.

60. De Winter BY, Robberecht P, Boeckxstaens GE, et al. Role of VIP1/ PACAP receptors in postoperative ileus in rats. $\mathrm{Br} J$ Pharmacol. 1998;124(6):1181-1186.

61. Boeckxstaens GE, Hollmann M, Heisterkamp SH, et al. Evidence for VIP(1)/PACAP receptors in the afferent pathway mediating surgery-induced fundic relaxation in the rat. Br J Pharmacol. 2000; 131(4):705-710.

62. Kälff JC, Türler A, Schwarz NT, et al. Intra-abdominal activation of a local inflammatory response within the human muscularis externa during laparotomy. Ann Surg. 2003;237(3):301-315.

63. Schwarz NT, Beer-Stolz D, Simmons RL, Bauer AJ. Pathogenesis of paralytic ileus: intestinal manipulation opens a transient pathway between the intestinal lumen and the leukocytic infiltrate of the jejunal muscularis. Ann Surg. 2002;235(1):31-40.

64. De Jonge WJ, The FO, van der Zanden EP, van den Wijngaard RM, Boeckxstaens GE. Inflammation and gut motility; neural control of intestinal immune cell activation. $J$ Pediatr Gastroenterol Nutr. 2005;41(Suppl 1):S10-S11. 
65. Kälff JC, Carlos TM, Schraut WH, Billiar TR, Simmons RL, Bauer AJ. Surgically induced leukocytic infiltrates within the rat intestinal muscularis mediate postoperative ileus. Gastroenterology. 1999;117(2):378-387.

66. The FO, de Jonge WJ, Bennink RJ, van der Wijngaard RM, Boeckxstaens GE. The ICAM-1 antisense oligonucleotide ISIS3082 prevents the development of postoperative ileus in mice. $\mathrm{Br} J$ Pharmacol. 2005;146(2):252-258.

67. Kälff JC, Buchholz BM, Eskandari MK, et al. Biphasic response to gut manipulation and temporal correlation of cellular infiltrates and muscle dysfunction in rats. Surgery. 1999;126(3):498-509.

68. Turler A, Moore BA, Pezzone MA, Overhaus M, Kalff JC, Bauer AJ. Colonic postoperative inflammatory ileus in the rat. Ann Surg. 2002;236(1):56-66.

69. Kreiss C, Toegel S, Bauer AJ. Alpha2-adrenergic regulation of NO production alters postoperative intestinal smooth muscle dysfunction in rodent. Am J Physiol Gastrointest Liver Physiol. 2004;287(3): G658-666.

70. Viscusi E, Rathmell J, Fichera A, Gan TL, Israel RJ. A double-blind, randomized, placebo-controlled trial of methylnaltrexone (MNTX) for post-operative bowel dysfunction in segmental colectomy patients [abstract]. Am Soc Anesth. 2005;103:A893.
71. Kraft MD. Methylnaltrexone, a new peripherally acting mu-opioid receptor antagonist being evaluated for the treatment of postoperative ileus. Expert Opin Investig Drugs. 2008;17(9):1365-1377.

72. Tan-No K, Niijima F, Nakagawasai O, Sato T, Satoh S, Tadano T. Development of tolerance to the inhibitory effect of loperamide on gastrointestinal transit in mice. Eur J Pharm Sci. 2003;20(3):357-363.

73. Ho EA, Piquette-Miller M. Regulation of multidrug resistance by pro-inflammatory cytokines. Curr Cancer Drug Targets. 2006;6(4):295-311.

74. Iizasa H, Genda N, Kitano T, et al. Altered expression and function of P-glycoprotein in dextran sodium sulfate-induced colitis in mice. J Pharm Sci. 2003;92(2):569-576.

75. Hartmann G, Kim H, Piquette-Miller M. Regulation of the hepatic multidrug resistance gene expression by endotoxin and inflammatory cytokines in mice. Int Immunopharmacol. 2001;1(2):189-199.

76. Heemskerk S, van Koppen A, van den Broek L, et al. Nitric oxide differentially regulates renal ATP-binding cassette transporters during endotoxemia. Pflugers Arch. 2007;454(2):321-334. 